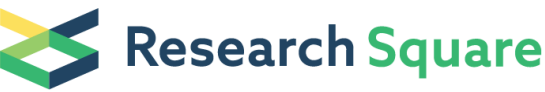

\section{A Genome-Wide Association Study for Melatonin Secretion}

Pi-Hua Liu

Chang Gung University

\section{Gwo-Tsann Chuang}

National Taiwan University Hospital, National Taiwan University

Chia-Ni Hsiung

Academia Sinica

Wei-Shun Yang

National Taiwan University Hospital Hsin-Chu branch

\section{Hsiao-Chia Ku}

National Taiwan University Hospital Hsin-Chu branch

Yi-Ching Lin

National Taiwan University Hospital Hsin-Chu branch

Yi-Shun Chen

National Taiwan University Hospital Hsin-Chu branch

Yu-Yao Huang

Chang Gung Memorial Hospital

Chia-Hung Lin

Chang Gung Memorial Hospital

Jou-Wei Lin

National Taiwan University Hospital Yun-Lin Branch

Chih-Neng Hsu

National Taiwan University Hospital Yun-Lin Branch

Juey-Jen Hwang

National Taiwan University Hospital Yun-Lin Branch

\section{Meng-Lun Hsieh}

National Taiwan University Hospital

Hsiao-Lin Lee

National Taiwan University Hospital

Chen-Yang Shen

Academia Sinica

Yi-Cheng Chang ( $\sim$ b83401040@gmail.com )

National Taiwan University

\section{Research Article}

Keywords: Melatonin, Genome-Wide Association Study

Posted Date: July 14th, 2021

DOI: https://doi.org/10.21203/rs.3.rs-687475/v1

License: (c) (i) This work is licensed under a Creative Commons Attribution 4.0 International License. Read Full License 


\section{Abstract}

\section{Summary}

Purpose: Melatonin exerts a wide range of effects among various tissues and organs. However, there is currently no study to investigate the genetic determinants of melatonin secretion. Here, we conducted a genome-wide association study (GWAS) for melatonin secretion using morning urine 6-hydroxymelatonin sulfate-to-creatinine ratio (UMCR).

Methods: We initially enrolled 5,000 participants from Taiwan Biobank in this study. After excluding individuals that did not have their urine collected in the morning and those who failed to pass quality control, association of single nucleotide polymorphisms with log-transformed UMCR adjusted for age, sex and principal components of ancestry were analyzed. A second model additionally adjusted for estimated glomerular filtration rate (eGFR).

Results: A total of 2,504 participants underwent the genome-wide analysis. Six candidate loci associated with log UMCR ( $P$ value ranging from $7.54 \times 10^{-7}$ to $4.65 \times 10^{-6}$ ) encompassing GALNT15, ZFHX3, NKAIN2, MME and NBPF22P were identified. Similar results were yielded with further adjustment for eGFR. Interestingly, the identified genes are associated with central nervous system function and clinical condition such as Alzheimer's disease or sleep disorders.

Conclusions: We conducted the first GWAS for melatonin secretion and identified six candidate genetic loci associated with melatonin level. Replication and functional studies are needed in the future.

\section{Introduction}

Melatonin is a pleiotropic hormone primarily synthesized and secreted from the pineal gland. It can also be produced by many other tissues including leukocytes, bone marrow, gastrointestinal tract, neuronal cells and gonads [1-3]. Melatonin regulates a range of physiological process including circadian and seasonal rhythms, energy and glucose metabolism, antioxidant effects, anti-inflammatory actions, and immune function [1, 3-6]. There are many studies showing associations between melatonin and many disorders, including certain types of mental illness, cancer, cardiovascular disease, metabolic syndrome, type 2 diabetes, and obesity [6-11]. Melatonin is secreted into the circulation following a circadian rhythm with peak levels at night [12]. Aging was once thought to be directly associated with decreased melatonin secretion. However, there was no significant difference between circadian amplitude of the plasma melatonin between healthy elderlies and young adults [13]. Instead of aging, the degree of pineal calcification was associated with melatonin excretion amount [14].

Substantial evidence suggests genetic factor also play a major role in melatonin secretion $[15,16]$. Genome-wide association study (GWAS) has been introduced as a powerful tool to identify common genetic variants of complex diseases or quantitative traits [17]. Currently there is no published GWAS regarding to melatonin level. Here, we conducted the first GWAS of urine melatonin metabolite, 6-hydroxymelatonin sulfate (aMT6s), which serves as an estimation of circulating melatonin level [18].

\section{Materials And Methods}

\section{Study population}

Five thousand individuals who are 30 to 70 years of age and without cancer history were enrolled from Taiwan Biobank. Biological specimens, personal and clinical information as delinked data were used in this study. This study was approved by the Institutional Review Board of Chang Gung Medical Foundation and the Institutional Review Board of National Taiwan University Hospital. All subjects have provided written informed consent and all methods were carried out in accordance with relevant guidelines and regulations.

\section{Urine aMT6s and creatinine measurement}

It is infeasible to draw blood samples from volunteers in the middle of the night for serum melatonin level. Urinary aMT6s is the major metabolite of melatonin excreted from the kidneys [19]. Thus, measuring morning urine aMT6s level is a practical 
alternative for serum melatonin level at night [18]. For better correlation, spot urine aMT6s level should be creatinine-corrected to adjust the effect of variable urinary dilution [20]. Urine aMT6s-to-creatinine ratio (UMCR) was calculated from urinary aMT6s divided by urine creatinine level. The concentration of aMT6s was measured in the urine of Taiwan Biobank subjects by an enzyme-linked immunosorbent assay (ELISA) kit using the manufacturer's protocol (Human Melatonin Sulfate ELISA kit, Elab science). No significant cross-reactivity or interference between melatonin sulfate and analogues was observed. All standards via serial dilution were assayed in duplicates. The urine creatinine level was measured using a chemistry analyzer (AU5800, Beckman Coulter) with compensated Jaffe method.

\section{Genotyping, quality control and imputation}

Genotyping with the Axiom-Taiwan Biobank Array Plate (TWB chip; Affymetrix Inc, Santa Clara, California) was performed at the National Center for Genome Medicine of Academia Sinica [21]. We use PLINK (version 1.07), an open-source whole-genome data analysis toolset, for quality control procedures [22]. For SNPs with batch effect, their genotypes were set as missing. SNPs were excluded if missing genotype rate was high ( $>5 \%)$, minor allele frequency was low $(<1 \%)$ or deviated from HardyWeinberg equilibrium $\left(P\right.$ value $\left.<10^{-5}\right)$. Individuals with high missing genotyping rate $(>5 \%)$, extreme heterozygosity rate (more than 5 standard deviations away from the mean) or high identity-by-descent score $(\geq 0.1875)$ implying close relatedness were excluded from subsequent analyses. We computed the principal components on a linkage disequilibrium (LD)-pruned $\left(r^{2}<0.2\right)$ set of autosomal variants obtained by removing high-LD regions via PLINK. Genotype imputation was carried out with SHAPEIT [23] and IMPUTE2 [24]. We applied1000 Genomes Project Phase 3 East Asian Ancestry as the reference population. For gene annotation, Genome Reference Consortium Human Build 37 was used. Imputed SNPs with low quality score (info score [25] lower than 0.3) were excluded. Indels were removed by using VCFtools [26].

\section{Statistical analyses}

Age and estimated glomerular filtration rate (eGFR) were expressed in terms of mean and standard deviation. Urine aMT6s and UMCR was expressed as median and interquartile range. Logarithmic transformation of UMCR was done to normalize the data. GWAS analysis was carried out via PLINK v1.07 with an additive genetic model. We applied linear regression for analyzing associations between SNPs and log UMCR. Covariate adjustment in Model 1 included age, sex and the first ten principal components of ancestry. eGFR was additionally adjusted in Model 2. We used a genome-wide significance threshold of $P<$ $5.0 \times 10^{-8}$ [27]. Since this threshold is very conservative for a small sample size, we set the level for suggestive significance at $P$ $<5 \times 10^{-6}[28,29]$. The Manhattan plot and quantile-quantile plot were generated by the qqman R package [30, 31]. Regional association plots were made via LocusZoom [32]. Using the following items, the proportion of phenotypic variance explained by SNP was calculated: effect size estimate of each minor allele on log UMCR, standard error of the effect size, sample size, and minor allele frequency for the SNP [33].The array-based heritability was estimated by LD score regression [34].

\section{Results}

Five thousand subjects were enrolled from Taiwan Biobank initially. One withdrew from the study. 2,361 did not have their urine collected in the morning and were excluded. 134 did not pass quality control procedures. After imputation and quality control, 7,897,704 autosomal SNPs remained. We performed a GWAS analysis for log UMCR in the remaining 2,504 subjects. The characteristics of our study population are listed in Table 1. Age is borderline significantly associated with log UMCR (Pearson's $r=0.038 ; P=0.057$ ). There is no significant gender difference of $\log U M C R$ shown by $T$ test (males 1.211, females $1.207 ; P=$ 0.819). eGFR is also not significantly associated with log UMCR (Pearson's $r=-0.001 ; P=0.943$ ). Variants with the strongest association in each region regarding to log UMCR are shown in Table 2. Melatonin production is known to be decreased with advanced chronic kidney disease [35]; thus, we adjusted eGFR additionally in Model 2. Figures 1 and 2 are the Manhattan plot and quantile-quantile plot. Regional association plots of the top SNPs are shown in Fig. 3. Six loci showed suggestive significance, with one near the GALNT15 gene on chromosome 3 ( $r$ 142037747; P = $7.54 \times 10^{-7}$, Fig. 3a), another within the ZFHX3 gene on chromosome 16 ( $r$ 17681554; $\mathrm{P}=3.29 \times 10^{-6}$, Fig. 3b), a third within the NKAIN2 gene on chromosome 6 (rs74760291; $\mathrm{P}=3.33 \times 10^{-6}$, Fig. 3c), a fourth near the MME gene on chromosome $3\left(\right.$ rs7433686; $P=4.09 \times 10^{-6}$, Fig. 3d), a 
fifth being intergenic on chromosome 14 (rs11625484; $\mathrm{P}=4.37 \times 10^{-6}$, Fig. 3e) and the other near the NBPF22P gene on chromosome 5 (rs76204167; P = $4.65 \times 10^{-6}$, Fig. 3f).

Table 1

Descriptive characteristics of study subjects

\begin{tabular}{|lc|}
\hline \multicolumn{2}{|l|}{ Characteristics } \\
\hline Total participants, $\mathrm{N}$ & 2,504 \\
\hline Age, year & $50.81 \pm 10.83$ \\
\hline Males, $\mathrm{N}(\%)$ & $925(36.94)$ \\
\hline eGFR, $\mathrm{ml} / \mathrm{min} / 1.73 \mathrm{~m}^{2}$ & $20.45(11.99-30.19)$ \\
\hline Urine aMT6s, $\mathrm{ng} / \mathrm{ml}$ & $17.00(10.37-27.40)$ \\
\hline UMCR, $\mathrm{ng} / \mathrm{mg}$ & 28.00 \\
\hline Data are mean $\pm \mathrm{SD}$, median (IQR) or number (\%), as appropriate. Age is at specimen \\
\hline collection. eGFR, estimated glomerular filtration rate (by Modification of Diet in Renal \\
\hline Disease equation); UMCR, urine aMT6s/creatinine ratio. \\
\hline
\end{tabular}

Table 2

Association of genetic loci with log UMCR in a Taiwan Han Chinese population

\begin{tabular}{|c|c|c|c|c|c|c|c|c|c|c|}
\hline \multirow[t]{2}{*}{ SNP } & \multirow[t]{2}{*}{ Chr } & \multirow[t]{2}{*}{ Position } & \multirow{2}{*}{$\begin{array}{l}\text { Nearest } \\
\text { gene }\end{array}$} & \multirow{2}{*}{$\begin{array}{l}\text { UMCR } \\
\text { increasing } \\
\text { allele }\end{array}$} & \multirow{2}{*}{$\begin{array}{l}\text { Other } \\
\text { allele }\end{array}$} & \multirow{2}{*}{$\begin{array}{l}\text { UMCR } \\
\text { increasing } \\
\text { allele } \\
\text { frequency }\end{array}$} & \multicolumn{2}{|c|}{ Model 1} & \multicolumn{2}{|c|}{ Model 2} \\
\hline & & & & & & & $\begin{array}{l}P \\
\text { value }\end{array}$ & $\begin{array}{l}\text { Beta } \\
\text { (SEM) }\end{array}$ & $\begin{array}{l}P \\
\text { value }\end{array}$ & $\begin{array}{l}\text { Beta } \\
\text { (SEM) }\end{array}$ \\
\hline rs142037747 & 3 & 16121712 & GALNT15 & G & $A$ & 0.989 & $\begin{array}{l}7.54 \\
x \\
10^{-7}\end{array}$ & $\begin{array}{l}0.249 \\
(0.050)\end{array}$ & $\begin{array}{l}7.46 \\
x \\
10^{-7}\end{array}$ & $\begin{array}{l}0.249 \\
(0.050)\end{array}$ \\
\hline rs17681554 & 16 & 73016768 & ZFHX3 & $A$ & $\mathrm{C}$ & 0.804 & $\begin{array}{l}3.29 \\
x \\
10^{-6}\end{array}$ & $\begin{array}{l}0.062 \\
(0.013)\end{array}$ & $\begin{array}{l}3.29 \\
x \\
10^{-6}\end{array}$ & $\begin{array}{l}0.062 \\
(0.013)\end{array}$ \\
\hline rs74760291 & 6 & 124526587 & NKAIN2 & $A$ & C & 0.941 & $\begin{array}{l}3.33 \\
x \\
10^{-6}\end{array}$ & $\begin{array}{l}0.108 \\
(0.023)\end{array}$ & $\begin{array}{l}3.34 \\
x \\
10^{-6}\end{array}$ & $\begin{array}{l}0.108 \\
(0.023)\end{array}$ \\
\hline rs7433686 & 3 & 155032307 & $M M E$ & $A$ & C & 0.610 & $\begin{array}{l}4.09 \\
x \\
10^{-6}\end{array}$ & $\begin{array}{l}0.051 \\
(0.011)\end{array}$ & $\begin{array}{l}4.04 \\
x \\
10^{-6}\end{array}$ & $\begin{array}{l}0.052 \\
(0.011)\end{array}$ \\
\hline rs11625484 & 14 & 43065019 & intergenic & $A$ & C & 0.050 & $\begin{array}{l}4.37 \\
x \\
10^{-6}\end{array}$ & $\begin{array}{l}0.050 \\
(0.011)\end{array}$ & $\begin{array}{l}4.33 \\
x \\
10^{-6}\end{array}$ & $\begin{array}{l}0.050 \\
(0.011)\end{array}$ \\
\hline rs76204167 & 5 & 85643507 & NBPF22P & $\mathrm{T}$ & C & 0.024 & $\begin{array}{l}4.65 \\
x \\
10^{-6}\end{array}$ & $\begin{array}{l}0.159 \\
(0.035)\end{array}$ & $\begin{array}{l}4.63 \\
x \\
10^{-6}\end{array}$ & $\begin{array}{l}0.159 \\
(0.035)\end{array}$ \\
\hline
\end{tabular}

The array-based heritability estimate for log UMCR is 0.1502 . Proportion of variance explained by the individual SNPs are $1.00 \%, 0.87 \%, 0.87 \%, 0.87 \%, 0.85 \%$ and $0.84 \%$ for rs 142037747 , rs 17681554 , rs 74760291 , rs 7433686, rs 11625484 and 


\section{Discussion}

In this first GWAS on melatonin secretion, we identified six suggestive loci that were associated with variation in log UMCR. rs142037747 is located near GALNT15 (polypeptide N-acetylgalactosaminyltransferase 15). GALNT15 catalyzes initiation of mucin-type O-linked glycosylation by adding $\mathrm{N}$-acetylgalactosamine to serine or threonine residues of the polypepide chain [36]. Glycosylation is associated with cell adhesion, signal transduction, molecular trafficking and differentiation in central nervous system development [37]. It remains to be determined whether and how GALNT15 significantly affects melatonin level.

rs17681554 is located within ZFHX3 (Zinc Finger Homeobox 3). ZFHX3 is a transcriptional regulator which contains four homeodomains and seventeen zinc fingers [38]. During neuronal differentiation, there is certain preferential expression pattern of ZFHX3 isoforms [39]. In addition, circadian behavior alteration is shown in inducible conditional Zfhx 3 knockout adult mice [40]. Further studies are needed to elucidate if there is a direct linkage between ZFHX3 and melatonin.

rs74760291 locates in the intronic region of NKAIN2 (sodium/potassium- transporting ATPase subunit beta-1-interacting protein). NKAIN2 is previously named T-cell lymphoma breakpoint-associated target protein 1 due to its association with lymphoma [41]. Genome-wide analyses demonstrated NKAIN2 gene in association with sleep quality and insomnia [42, 43]. Since darkness is the most important regulator of melatonin secretion and light drastically reduced melatonin across the day, melatonin also reciprocally affected sleep quality and insomnia in large-scale meta-analysis [44]. From our study, it is highly likely that genetic variation of NKAIN2 affects sleep via affecting melatonin secretion. However, further study is warranted as we cannot exclude the reverse causation that NKAIN2 variation-associated sleep order results in disturbed melatonin secretion.

rs7433686 is located near $M M E$ (membrane metalloendopeptidase; more commonly known as neprilysin). Neprilysin degrades amyloid beta-protein, which is the main constituent of amyloid plaques seen in patients with Alzheimer's disease (AD) [45]. A candidate gene-based association study suggested neprilysin was a susceptibility gene for $A D$ [46]. Melatonin levels are altered in AD patients, possibly due to a decrease in suprachiasmatic nucleus cell number and functional pineal gland volume [47]. Our present unbiased genetic study, revealing the $M M E$ variant associated with melatonin secretion from pineal gland, provides additional evidence for potential mechanistic explanation in AD patients with altered melatonin levels.

rs11625484 is an intergenic SNP. Whether long non-coding RNAs or microRNAs encoded in this intergenic region might affect melatonin levels remains to be elucidated.

rs76204167 is located near NBPF22P (neuroblastoma breakpoint family, member 22, pseudogene). Members of NBPF are likely to be involved in neuronal development besides cancer occurrence [48]. A previous GWAS regarding to actigraphy-based sleep parameters has shown NBPF22P related to sleep quality [49]. The exact mechanism of relation between NBPF22P and melatonin is to be explored.

This study also showed borderline significance regarding to the positive correlation between age and log UMCR. Since aging causes sarcopenia, subsequent decreased creatinine excretion from urine tends to increase the substance-to-creatinine ratio. Our result support the current concept that aging itself will not cause a decrease in melatonin secretion or excretion.

There was a concern that aMT6s excretion may be altered when renal function declines. A previous study enrolling 20 elderlies demonstrated that 24-hour urine aMT6s was a reliable surrogate for plasma melatonin level, at least among individuals with GFR $24.6 \mathrm{ml} / \mathrm{min}$ or above [50]. Our study confirmed that morning UMCR is not significantly correlated with eGFR, and adjusting eGFR in GWAS analysis essentially did not have influence on the results.

There are limitations of our study. First, it lacks replication of the result in another cohort. We searched in the UK Biobank, but melatonin as phenotype does not exist in the database. Moreover, the sample size is relatively small, thus for the time being these SNPs can be only seen as suggestive signals, and true loci remain to be identified and validated. 
In summary, we have performed the first GWAS regarding to melatonin secretion to date. This GWAS identified 6 highly suggested genetic loci encompassing genes that had been demonstrated potential functional connectivity between the genesassociated melatonin level and clinical documented disorders such as AD and sleep disorders. Replication and functional studies of these genetic variations are warranted to better understand the regulation of melatonin secretion and related clinical disorders.

\section{Declarations}

\section{Acknowledgements}

This work is supported by grants from the Ministry of Science and Technology in Taiwan (MOST 105-2314-B-182-062, MOST 106-2314-B-182-043), the Translational Medical Research Program of Academia Sinica (ASTM-108-01-04), National Taiwan University Hospital, Yunlin Branch Intramural Grant $(2016,2017,2020)$ and Chang Gung University, Taoyuan, Taiwan (NMRPD1F154, NMRPD1G0711, and BMRPD08). We would like to thank Taiwan Biobank for providing the biological specimens and information for our research. We would also like to thank Professor Lee-Ming Chuang at the Department of Internal Medicine, National Taiwan University Medical College for the critical review and valuable discussion about this manuscript. Lastly, we thank the Data Science Statistical Cooperation Center of Academia Sinica (AS-CFII-108-117) for statistical support.

\section{Author contributions}

P.H.L., G.T.C. and Y.C.C. contributed to the experimental design. Y.S.W., H.C.K., Y.C.L., Y.S.C., Y.Y.H., C.H.L., J.W.L., Chih-Neng H., J.J.H, M.L.H., H.L.L. and Y.C.C. contributed to sample procurement and data generation. G.T.C. was responsible for data analysis; P.H.L., Chia-Ni H. and C.Y.S. provided technical help. Manuscript writing was done by G.T.C., P.H.L. and Y.C.C.

\section{Conflict of Interest Statement}

The authors declare no conflicts of interest.

\section{Data availability}

Individual researchers may request to use the data for specific projects on a collaborative basis.

\section{Bioethics Statement}

This study was approved by the Institutional Review Board of Chang Gung Medical Foundation and the Institutional Review Board of National Taiwan University Hospital. All subjects have provided written informed consent and all methods were carried out in accordance with relevant guidelines and regulations.

\section{References}

1. Galano A, Tan DX \& Reiter RJ. Melatonin as a natural ally against oxidative stress: a physicochemical examination. Journal of Pineal Research 201151 1-16.

2. Hardeland R, Cardinali DP, Srinivasan V, Spence DW, Brown GM \& Pandi-Perumal SR. Melatonin-a pleiotropic, orchestrating regulator molecule. Progress in Neurobiology 201193 350-384.

3. Favero G, Rodella LF, Reiter RJ \& Rezzani R. Melatonin and its atheroprotective effects: a review. Molecular and Cellular Endocrinology 2014382 926-937.

4. Reiter RJ. Melatonin: clinical relevance. Best Practice \& Research Clinical Endocrinology and Metabolism $200317273-285$.

5. Claustrat B, Brun J \& Chazot G. The basic physiology and pathophysiology of melatonin. Sleep Medicine Reviews 2005 9 11-24. 
6. Nduhirabandi F \& Lochner A. Melatonin and the metabolic syndrome. In: Melatonin and Melatonergic Drugs in Clinical Practice, edn 1, ch. 6, pp 71-95. Eds V Srinivasan, A Brzezinski, S Oter \& SD Shillcutt. New Delhi: Springer India, 2014.

7. Peschke E. Melatonin, endocrine pancreas and diabetes. Journal of Pineal Research 2008 44 26-40.

8. Tengattini S, Reiter RJ, Tan DX, Terron MP, Rodella LF \& Rezzani R. Cardiovascular diseases: protective effects of melatonin. Journal of Pineal Research 200844 16-25.

9. Espino J, Pariente JA \& Rodríguez AB. Role of melatonin on diabetes-related metabolic disorders. World Journal of Diabetes 20112 82-91.

10. Hardeland R, Madrid JA, Tan DX \& Reiter RJ. Melatonin, the circadian multioscillator system and health: the need for detailed analyses of peripheral melatonin signaling. Journal of Pineal Research 2012 52 139-166.

11. Sigurdardottir LG, Markt SC, Rider JR, Haneuse S, Fall K, Schernhammer ES, Tamimi RM, Flynn-Evans E, Batista JL, Launer $\mathrm{L}$ et al. Urinary melatonin levels, sleep disruption, and risk of prostate cancer in elderly men. European Urology 2015 67 191-194.

12. Arendt J. Melatonin: characteristics, concerns, and prospects. Journal of Biological Rhythms 2005 20 291-303.

13. Zeitzer JM, Daniels JE, Duffy JF, Klerman EB, Shanahan TL, Dijk DJ \& Czeisler CA. Do plasma melatonin concentrations decline with age? The American Journal of Medicine 1999107 432-436.

14. Kunz D, Schmitz S, Mahlberg R, Mohr A, Stöter C, Wolf KJ \& Herrmann WM. A new concept for melatonin deficit: on pineal calcification and melatonin excretion. Neuropsychopharmacology: official publication of the American College of Neuropsychopharmacology 199921 765-772.

15. Wetterberg L, Iselius L \& Lindsten J. Genetic regulation of melatonin excretion in urine. A preliminary report. Clinical Genetics 198324 399-402.

16. Hallam KT, Olver JS, Chambers V, Begg DP, McGrath C \& Norman TR. The heritability of melatonin secretion and sensitivity to bright nocturnal light in twins. Psychoneuroendocrinology 200631 867-875.

17. McCarthy MI, Abecasis GR, Cardon LR, Goldstein DB, Little J, loannidis JP \& Hirschhorn JN. Genome-wide association studies for complex traits: consensus, uncertainty and challenges. Nature Reviews Genetics $20089356-369$.

18. Graham C, Cook MR, Kavet R, Sastre A \& Smith DK. Prediction of nocturnal plasma melatonin from morning urinary measures [published correction appears in Journal of Pineal Research 199926 128]. Journal of Pineal Research 1998 $24230-238$.

19. Kopin IJ, Pare CM, Axelrod J \& Weissbach H. The fate of melatonin in animals. The Journal of Biological Chemistry 1961 $2363072-3075$.

20. Klante G, Brinschwitz T, Secci K, Wollnik F \& Steinlechner S. Creatinine is an appropriate reference for urinary sulphatoxymelatonin of laboratory animals and humans. Journal of Pineal Research. 199723 191-197.

21. Chen $\mathrm{CH}$, Yang JH, Chiang C, Hsiung CN, Wu PE, Chang LC, Chu HW, Chang J, Song IW, Yang SL et al. Population structure of Han Chinese in the modern Taiwanese population based on 10,000 participants in the Taiwan Biobank project. Human Molecular Genetics 201625 5321-5331.

22. Purcell S, Neale B, Todd-Brown K, Thomas L, Ferreira MA, Bender D, Maller J, Sklar P, de Bakker PI, Daly MJ et al. PLINK: a tool set for whole-genome association and population-based linkage analyses. American Journal of Human Genetics 2007 $81559-575$.

23. Delaneau O, Zagury JF \& Marchini J. Improved whole-chromosome phasing for disease and population genetic studies. Nature Methods 201310 5-6.

24. Howie B, Fuchsberger C, Stephens M, Marchini J \& Abecasis GR. Fast and accurate genotype imputation in genome-wide association studies through pre-phasing. Nature Genetics 201244 955-959.

25. Marchini J \& Howie B. Genotype imputation for genome-wide association studies. Nature Reviews Genetics $201011499-$ 511.

26. Danecek P, Auton A, Abecasis G, Albers CA, Banks E, DePristo MA, Handsaker RE, Lunter G, Marth GT, Sherry ST et al. The variant call format and VCFtools. Bioinformatics (Oxford, England) 201127 2156-2158.

Page $7 / 10$ 
27. Pe'er I, Yelensky R, Altshuler D \& Daly MJ. Estimation of the multiple testing burden for genomewide association studies of nearly all common variants. Genetic Epidemiology 200832 381-385.

28. Fallin MD \& Kao WH. Is "X"-WAS the future for all of epidemiology? [published correction appears in Epidemiology 2011 22 881]. Epidemiology 201122 457-468.

29. Duggal P, Gillanders EM, Holmes TN \& Bailey-Wilson JE. Establishing an adjusted p-value threshold to control the familywide type 1 error in genome wide association studies. BMC Genomics 20089516.

30. Turner S. qqman: an R package for visualizing GWAS results using Q-Q and manhattan plots. Journal of Open Source Software 20183731.

31. R Core Team. R: A Language and Environment for Statistical Computing. Vienna: R Foundation for Statistical Computing, 2018.

32. Pruim RJ, Welch RP, Sanna S, Teslovich TM, Chines PS, Gliedt TP, Boehnke M, Abecasis GR \& Willer CJ. LocusZoom: regional visualization of genome-wide association scan results. Bioinformatics (Oxford, England) $2010262336-2337$.

33. Shim H, Chasman DI, Smith JD, Mora S, Ridker PM, Nickerson DA, Krauss RM \& Stephens M. A multivariate genome-wide association analysis of $10 \mathrm{LDL}$ subfractions, and their response to statin treatment, in 1868 Caucasians. PLoS One 2015 $10: \mathrm{e} 0120758$.

34. Bulik-Sullivan BK, Loh PR, Finucane HK, Ripke S, Yang J; Schizophrenia Working Group of the Psychiatric Genomics Consortium, Patterson N, Daly MJ, Price AL \& Neale BM. LD Score regression distinguishes confounding from polygenicity in genome-wide association studies. Nature Genetics 201547 291-295.

35. Koch BC, van der Putten K, Van Someren EJ, Wielders JP, Ter Wee PM, Nagtegaal JE \& Gaillard CA. Impairment of endogenous melatonin rhythm is related to the degree of chronic kidney disease (CREAM study). Nephrology, Dialysis, Transplantation: Official Publication of the European Dialysis and Transplant Association - European Renal Association 201025 513-519.

36. Cheng L, Tachibana K, Iwasaki H, Kameyama A, Zhang Y, Kubota T, Hiruma T, Tachibana K, Kudo T, Guo JM \& Narimatsu H. Characterization of a novel human UDP-GaINAc transferase, pp-GalNAc-T15. FEBS Letters 2004566 17-24.

37. Iqbal S, Ghanimi Fard M, Everest-Dass A, Packer NH \& Parker LM. Understanding cellular glycan surfaces in the central nervous system. Biochemical Society Transactions 201947 89-100.

38. Morinaga T, Yasuda H, Hashimoto T, Higashio K \& Tamaoki T. A human alpha-fetoprotein enhancer-binding protein, ATBF1, contains four homeodomains and seventeen zinc fingers. Molecular and Cellular Biology 199111 6041-6049.

39. Miura Y, Tam T, Ido A, Morinaga T, Miki T, Hashimoto T \& Tamaoki T. Cloning and characterization of an ATBF1 isoform that expresses in a neuronal differentiation-dependent manner. The Journal of Biological Chemistry 199527026840 26848.

40. Wilcox AG, Vizor L, Parsons MJ, Banks G \& Nolan PM. Inducible Knockout of Mouse Zfhx3 Emphasizes Its Key Role in Setting the Pace and Amplitude of the Adult Circadian Clock. Journal of Biological Rhythms $201732433-443$.

41. Tagawa H, Miura I, Suzuki R, Suzuki H, Hosokawa Y \& Seto M. Molecular cytogenetic analysis of the breakpoint region at 6q21-22 in T-cell lymphoma/leukemia cell lines. Genes, Chromosomes \& Cancer 200234 175-185.

42. Jones SE, van Hees VT, Mazzotti DR, Marques-Vidal P, Sabia S, van der Spek A, Dashti HS, Engmann J, Kocevska D, Tyrrell $\mathrm{J}$ et al. Genetic studies of accelerometer-based sleep measures yield new insights into human sleep behaviour. Nature Communications 2019101585.

43. Jansen PR, Watanabe K, Stringer S, Skene N, Bryois J, Hammerschlag AR, de Leeuw CA, Benjamins JS, Muñoz-Manchado $A B$, Nagel $M$ et al. Genome-wide analysis of insomnia in 1,331,010 individuals identifies new risk loci and functional pathways. Nature Genetics 201951 394-403.

44. Fatemeh G, Sajjad M, Niloufar R, Neda S, Leila S \& Khadijeh M. Effect of melatonin supplementation on sleep quality: a systematic review and meta-analysis of randomized controlled trials [published online ahead of print, 2021 Jan 8]. Journal of Neurology 2021 doi:10.1007/s00415-020-10381-w. 
45. Leissring MA, Lu A, Condron MM, Teplow DB, Stein RL, Farris W \& Selkoe DJ. Kinetics of amyloid beta-protein degradation determined by novel fluorescence- and fluorescence polarization-based assays. The Journal of Biological Chemistry 2003 278 37314-37320.

46. Helisalmi S, Hiltunen M, Vepsäläinen S, livonen S, Mannermaa A, Lehtovirta M, Koivisto AM, Alafuzoff I \& Soininen H. Polymorphisms in neprilysin gene affect the risk of Alzheimer's disease in Finnish patients. Journal of Neurology, Neurosurgey, and Psychiatry 200475 1746-1748.

47. Nous A, Engelborghs $S \&$ Smolders I. Melatonin levels in the Alzheimer's disease continuum: a systematic review. Alzheimer's Research \& Therapy 20211352 doi:10.1186/s13195-021-00788-6.

48. Andries V, Vandepoele K \& van Roy F. The NBPF Gene Family. In: Neuroblastoma-Present and Future, edn 1, ch. 9, pp 185214. Eds H Shimada. Rijeka, Croatia: InTech, 2012.

49. Spada J, Scholz M, Kirsten H, Hensch T, Horn K, Jawinski P, Ulke C, Burkhardt R, Wirkner K, Loeffler M et al. Genome-wide association analysis of actigraphic sleep phenotypes in the LIFE Adult Study. Journal of Sleep Research 201625 690-701.

50. Baskett JJ, Cockrem JF \& Antunovich TA. Sulphatoxymelatonin excretion in older people: relationship to plasma melatonin and renal function. Journal of Pineal Research. 199824 58-61.

\section{Figures}

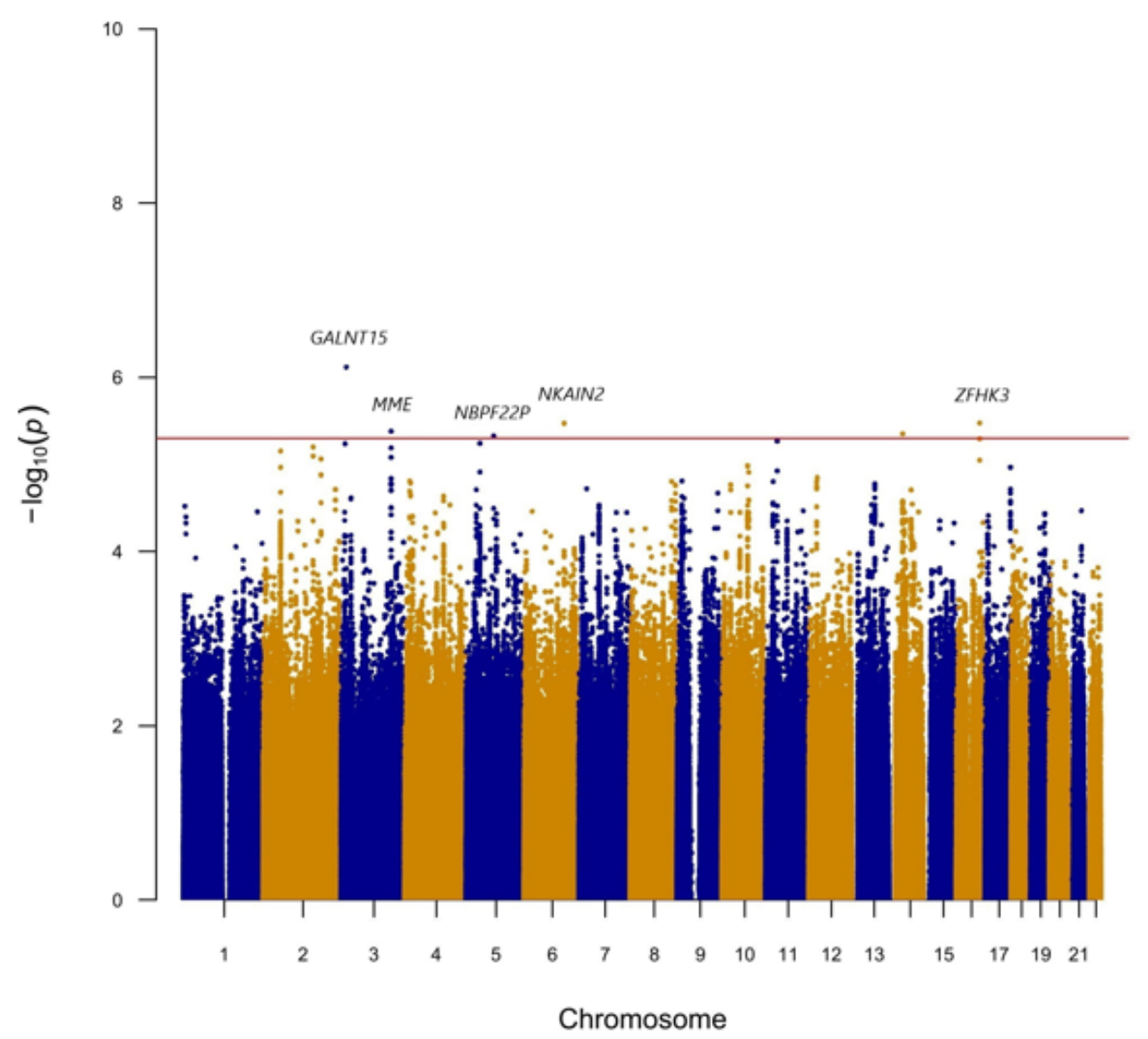

Figure 1

Manhattan plot of the GWAS results for log UMCR. SNPs are plotted on the $x$ axis according to their chromosome position against association with log UMCR on the $y$ axis. The red horizontal line represents the suggestive association threshold of $\mathrm{P}=$ 


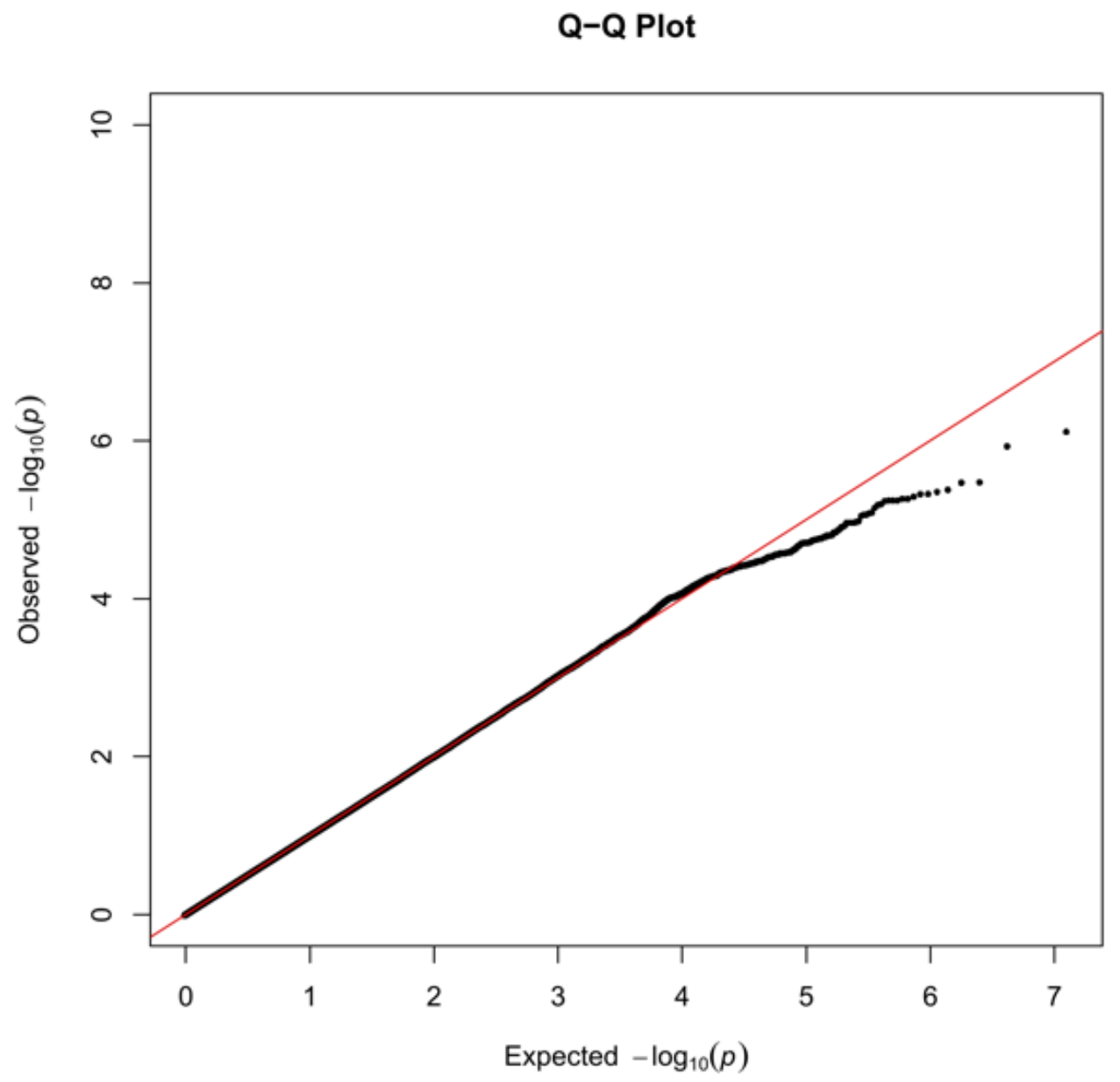

Figure 2

Quantile-quantile plots of log UMCR.

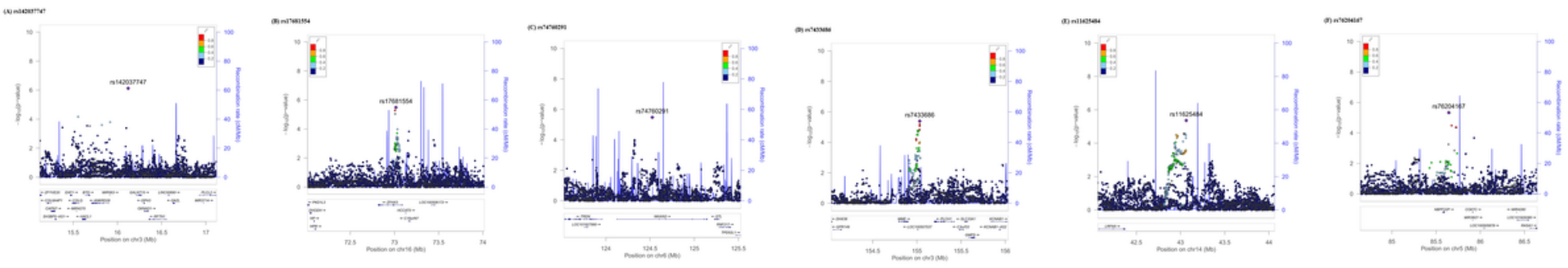

Figure 3

Regional association plots of log UMCR. (A) rs142037747 (B) rs17681554 (C) rs74760291 (D) rs7433686 (E) rs11625484 (F) rs76204167. 